\title{
Neocortical Chandelier Cells Developmentally Shape Axonal Arbors through Reorganization but Establish Subcellular Synapse Specificity without Refinement
}

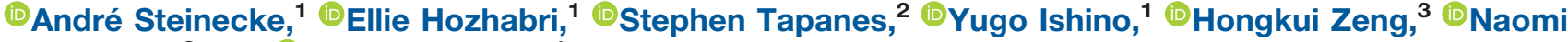 \\ Kamasawa, ${ }^{2}$ and ${ }^{-}$Hiroki Taniguchi ${ }^{1}$
}

DOI:http://dx.doi.org/10.1523/ENEURO.0057-17.2017

${ }^{1}$ Development and Function of Inhibitory Neural Circuits, Max Planck Florida Institute for Neuroscience, Jupiter, FL 33458, ${ }^{2}$ Electron Microscopy Facility, Max Planck Florida Institute for Neuroscience, Jupiter, FL 33458, and ${ }^{3}$ Allen Institute for Brain Science, Seattle, WA 98103

\section{Visual Abstract}
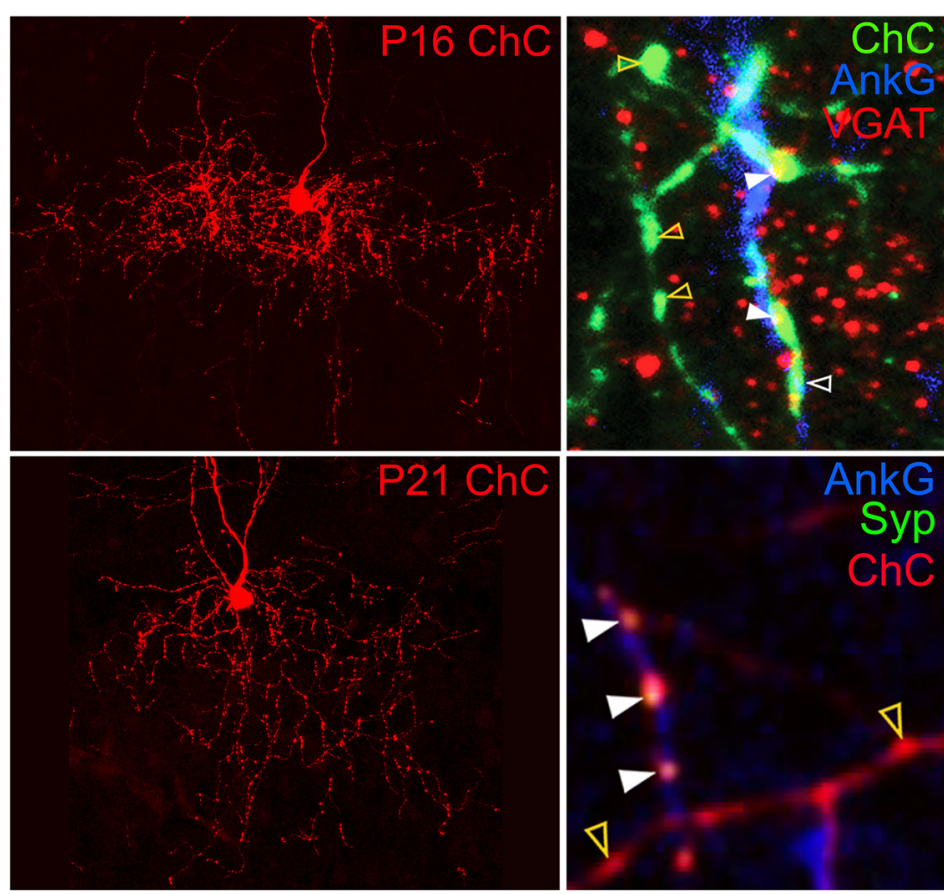

Diverse types of cortical interneurons (INs) mediate various kinds of inhibitory control mechanisms to balance and shape network activity. Distinct IN subtypes develop uniquely organized axonal arbors that innervate different subcellular compartments of excitatory principal neurons (PNs), which critically contribute to determining their output properties. However, it remains poorly understood how they establish this peculiar axonal organization and synaptic connectivity during development. Here, taking advantage of genetic labeling of IN progenitors, we examined developmental processes of axonal arbors and synaptic connections formed by murine chandelier cells (ChCs), which innervate axon initial segments (AISs) of PNs and thus powerfully regulate their spike generation. Our quantitative analysis by light microscopy revealed that $\mathrm{ChCs}$ overgrow and subsequently refine axonal branches as well as varicosities. Interestingly, we found that although a significant number of axonal varicosities are formed off AISs in addition to on AISs, presynaptic markers are predominantly colo-

\section{Significance Statement}

Highly structured axonal arbors with subcellular synapse specificity are one of the most striking features of cortical interneuron (IN) circuits. However, little is known about the developmental processes through which IN subtypes establish axonal and synaptic organization. Addressing this question required technical innovations that allowed us to follow the developmental time course of a uniform IN subtype at a single cell level. Using genetic targeting of chandelier cell $(\mathrm{ChC})$ progenitors, we provided evidence that developing ChCs form synapses specifically on their subcellular targets, axon initial segments (AISs) of PNs, despite transient overgrowth of axonal branches and varicosities. Our results suggest that subcellular synapse specificity of ChCs is genetically predetermined while axonal geometry is established through refinement. 
calized with those on AISs throughout development. Immunoelectron microscopic (IEM) analysis also demonstrated that only varicosities apposed to AISs contain presynaptic profiles. These results suggest that subcellular synapse specificity of $\mathrm{ChCs}$ is genetically predetermined while axonal geometry is shaped through remodeling. Molecular cues localized at AISs may regulate target recognition and synapse formation by ChCs.

Key words: axon initial segment; axonal remodeling; chandelier cell; cortical interneuron; subcellular synapse specificity

\section{Introduction}

Higher-order cortical functions such as sensory processing, learning, and memory rely on precise wiring of cortical circuits that consist of excitatory principal neurons (PNs) and inhibitory interneurons (INs). Cortical INs not only balance overall network activity but also control PN spatiotemporal activity patterns, which are essential for cortical processing and representation of information (Markram et al., 2004; Klausberger and Somogyi, 2008; Kepecs and Fishell, 2014). Despite such a critical role for INs in cortical network operations, the developmental principles for IN wiring are poorly understood.

INs comprise diverse classes, which differ in morphology, physiology, gene expression, and connectivity, enabling various types of neural computations (Jonas et al., 2004; Markram et al., 2004; DeFelipe et al., 2013; Kepecs and Fishell, 2014). Mature IN subtypes display unique geometry of axonal arbors and specifically deploy synaptic terminals to distinct subcellular domains [e.g., dendrites, somata, or axon initial segments (AISs)] of PNs (Somogyi et al., 1998; Karube et al., 2004; Huang et al., 2007; Jiang et al., 2015). Such highly specialized axonal and synaptic organization contributes to determining the output properties of each IN subtype. Despite this crucial anatomic basis for inhibitory circuit function, the developmental processes of IN wiring are largely unknown. Addressing this question has been hampered by the extreme diversity of cell types and the lack of methods to target morphologically uniform IN subtypes. In addition, inability to clearly visualize subdomains of PNs has prevented our understanding of IN wiring mechanisms.

Received February 20, 2017; accepted April 26, 2017; First published May 02, 2017.

The authors declare no competing financial interests.

Author contributions: H.T. and A.S. designed research; A.S., S.T., and N.K. performed research; H.Z., E.H., and Y.I. contributed unpublished reagents/ analytic tools; A.S., S.T., N.K., and H.T. analyzed data; A.S. and H.T. wrote the paper.

This work was supported by funding from the Max Planck Society and Whitehall Foundation.

Acknowledgements: We thank Dr. Z. Josh Huang for allowing H.T. to bring mouse lines including Nkx2.1-CreER, Ai14, and LSL-tGFP mice to his own new laboratory. We also thank Dr. Ryohei Yasuda, Dr. David Fitzpatrick, Dr. Elly Nedivi, Dr. Z. Josh Huang, and members of the H.T. laboratory for critical reading of this manuscript and comments.

Correspondence should be addressed to Hiroki Taniguchi, Max Planck Florida Institute for Neuroscience, Development and Function of Inhibitory Neural Circuits, One Max Planck Way, Jupiter, FL 33458, E-mail: hiroki.taniguchi@mpfi.org.

DOI:http://dx.doi.org/10.1523/ENEURO.0057-17.2017

Copyright (C) 2017 Steinecke et al.

This is an open-access article distributed under the terms of the Creative Commons Attribution 4.0 International license, which permits unrestricted use, distribution and reproduction in any medium provided that the original work is properly attributed.
Cortical chandelier cells (ChCs) are one of the most distinct and uniform IN subtypes (Howard et al., 2005; Woodruff et al., 2010). ChC axons exhibit a characteristic geometry with many prominent vertical branches, whose terminals are specialized into strings of synaptic varicosities (cartridges) directly apposed to AISs of PNs (Jones, 1975; Szentagothai, 1975; Somogyi, 1977). Because the AIS is the site of action potential initiation, ChCs can have decisive control over spike generation in a PN ensemble, thereby regulating synchrony and oscillation of network activity (Klausberger et al., 2003; Szabadics et al., 2006; Glickfeld et al., 2009). The striking stereotypy and specificity of this axonal and synaptic organization make ChCs an ideal system to study basic cellular events of IN wiring, such as axonal branching and subcellular synapse targeting. Another advantage is that individual AISs, which can be labeled with AIS-specific markers such as anti-AnkyrinG (AnkG) antibodies, can be unambiguously identified because they are spatially separable from neighboring AISs (Jenkins and Bennett, 2001; Taniguchi et al., 2013).

Several studies established genetic strategies to reliably label ChCs, which target ChC progenitors in the medial ganglionic eminence (MGE; Inan et al., 2013; Taniguchi et al., 2013). Young ChCs migrate along stereotyped routes with a defined schedule to settle at the border between layer 1 (L1) and L2, and in L5/6 (Taniguchi et al., 2013). ChCs mostly establish mature axonal and synaptic organization by postnatal day $(\mathrm{P}) 18$ and modify their arbors with minor lateral axonal expansions and small increases in the number of cartridges toward P30 (Inan et al., 2013). However, the developmental processes through which ChCs establish unique axonal organization and subcellular synapse specificity have not been explored.

In this study, taking advantage of genetic labeling of $\mathrm{ChC}$ progenitors, we examined the developmental time course of axonal and synaptic organization and determined how axonal geometry and subcellular synapse specificity of ChCs emerge during postnatal development. We found that ChCs form excessive axonal branches and varicosities, which are remodeled via pruning. Furthermore, we demonstrate that although ChCs develop exuberant varicosities off AISs as well as on AISs, their synapses are specifically formed at AIS varicosities. Our results indicate that subcellular synapse specificity of ChCs is genetically programmed while axonal arbors are established through reorganization.

\section{Materials and Methods}

All experimental procedures using live animals were approved by the IACUC of Max Planck Florida Institute for Neuroscience and performed in accordance with institutional and federal guidelines. The mice were kept under $12 / 12 \mathrm{~h}$ light/dark cycles and housed in standard cages 
with water and food ad libitum. Embryonic day 0 (EO) and PO are defined by the day of plug and the day of birth, respectively.

\section{Mouse strains}

Nkx2.1-CreER (JAX Stock 014552) and LSL-RFP (Ai14; JAX Stock 007914) mice are available from The Jackson Laboratory. In the LSL-triple green fluorescent protein (LSL-tGFP) mouse line, the Rosa26 locus has been modified by targeted insertion of a construct containing the strong and ubiquitously active CAG promoter, a loxPflanked stop cassette, a triple GFP gene unit, a woodchuck hepatitis virus posttranscriptional regulatory element (WPRE), and a poly $A$ signal. The triple GFP unit was generated by gene synthesis (Genscript) and contains sequences for Emerald GFP (Life Technologies), TagGFP2 (Evrogen) and humanized Renilla GFP variants, which have been linked together by viral T2A and P2A oligopeptide sequences. The LSL-tGFP targeting construct was transfected into the 129S6B6F1 hybrid ES cell line G4, and correctly targeted clones were identified by PCR and Southern blot screening, then injected into C57BL/6J blastocysts to obtain chimeras for eventual germline breeding. The resulting mice were crossed to the Rosa26-PhiC31 line (JAX Stock \#007743) to delete the PGK-Neo selection cassette through PhiC31mediated recombination between the AttB and AttP recombinase sites in the germline of the mice. Ai14/+ and LSL$t G F P /+$ mouse strains were backcrossed with Swiss Webster (SW) mice for at least three generations before obtaining homozygotes. The Ai14/Ai14 and LSL-tGFP/LSLtGFP homozygous colonies were maintained by inbreeding. Nkx2.1-CreER;Ai14/Ai14 and Nkx2.1-CreER; LSL-tGFP/ LSL-tGFP mouse lines, which originally had had a mixed genetic background (SW and 129/B6), were outbred with the Ai14/Ai14 and LSL-tGFP/LSL-tGFP homozygotes, respectively, for more than three generations. To obtain Nkx2.1CreER;Ai14/+ and Nkx2.1-CreER; LSL-tGFP/+ mice for experiments, Nkx2.1-CreER;Ai14/Ai14 and Nkx2.1-CreER; LSL-tGFP/LSL-tGFP male mice, respectively, were crossed with $S W$ female mice. Both males and females were used in this study.

\section{Tamoxifen (Tmx) induction}

Tmx was administered to timed pregnant SW females that were bred to Nkx2.1-CreER;Ai14/Ai14 or Nkx2.1CreER; LSL-tGFP/LSL-tGFP males by oral gavage at E17 to induce CreER activity in the offspring. To achieve sparse labeling of ChCs the dose was adjusted to 0.15 $\mathrm{mg} / 30 \mathrm{~g}$ of body weight. Tmx solution was prepared at a working concentration of $2 \mathrm{mg} / \mathrm{ml}$ in corn oil (Sigma), protected from light, and kept refrigerated for no longer than one month.

\section{Electroporation of dissociated MGE cells and transplantation}

Timed pregnant SW mice were deeply anesthetized at E17 using isoflurane. After cervical dislocation the uterus was dissected and kept in AdvanceSTEM ES qualified DPBS (GE). The embryonic brains were dissected and cut into 400- $\mu \mathrm{m}$ sections using a tissue chopper (Intra Cell). Brain slices were kept in Hibernate buffer [Hibernate-E
(Gibco), 100× GlutaMAX (Gibco), 50× B27 supplement (Gibco)], and the ventral MGE was dissected and collected in $1 \mathrm{ml}$ Hibernate buffer. After a 10-min incubation in trypsin solution (Sigma-Aldrich) at $37^{\circ} \mathrm{C}$ and the addition of $10 \%$ FBS final concentration (Sigma-Aldrich) the tissue was spun down for $5 \mathrm{~min}$ at $500 \mathrm{rpm}$ and resuspended in OptiMEM (Gibco). Subsequently, the cells were spun down as before and resuspended in $100 \mu \mathrm{l}$ of OptiMEM containing $25 \mu \mathrm{g}$ of $p C B H-Z s$ Green or $p C A G-D s R e d$ $+p C A G-S y p-Y F P$ vector DNA. The cell suspension was transferred to a cuvette (Bulldog Bio 2-mm gap aluminum cuvettes, catalog 12358-346) and electroporated (Nepa Gene; poring: 275 V, 0.3-ms duration, $50-\mathrm{ms}$ interval, 5 pulses, $10 \%$ decay; transfer: $20 \mathrm{~V}, 50-\mathrm{ms}$ duration, $50-\mathrm{ms}$ interval, 5 pulses, $40 \%$ decay). The cells were spun down as before, resuspended in $10 \mu \mathrm{l}$ of Hibernate buffer at a density of $100,000 \mathrm{cells} / \mu \mathrm{l}$, and kept on ice.

P1 SW mice were anesthetized on ice for $5 \mathrm{~min}$ and the absence of pain perception was assured. A total of $10,000-20,000$ cells were injected at $0.2 \mathrm{~mm}$ anterior and $0.2 \mathrm{~mm}$ lateral of bregma between 150 and $300 \mu \mathrm{m}$ in depth using pulled glass pipets (Warner Instruments) in combination with a stereotactic apparatus (Kopf) and a picospritzer (Parker). The incision was closed with vet bond (Patterson Veterinary) and the pups were placed on a heating plate at $37^{\circ} \mathrm{C}$ until full recovery.

Many of the transplanted cells migrated from the somatosensory cortex (SSC) and settled in the medial prefrontal cortex (mPFC) and anterior cingulate cortex (ACC). Among transplanted ZsGreen or DsRed-expressing cells, $\sim 30 \%$ were ChCs; the rest were other INs (data not shown). They were largely located in expected laminar positions (L2, L5, and L6).

\section{Immunohistochemistry, imaging, and three- dimensional (3D) reconstruction}

Mice were deeply anesthetized with an IP injection of ketamine and xylazine $(50 \mathrm{mg} / \mathrm{kg}$ ketamine, Vetco, 5 $\mathrm{mg} / \mathrm{kg}$ xylazine, Akorn) and transcardially perfused with $15 \mathrm{ml}$ cold $0.9 \%$ saline solution followed by $20 \mathrm{ml} 4 \%$ PFA in PBS. Brains were dissected and postfixed in $2 \%$ PFA overnight at $4{ }^{\circ} \mathrm{C}$ and afterward stored in PBS until further use. $60 \mu \mathrm{m}$ coronal brain sections were prepared using a vibratome (Leica), permeabilized in $0.5 \%$ Triton X-100 in PBS for 10 min followed by blocking in $0.1 \%$ Triton X-100, $10 \%$ donkey serum (Jackson ImmunoResearch) in PBS for $1 \mathrm{~h}$. Subsequently, slices were incubated with primary antibodies in blocking solution over night at $4^{\circ} \mathrm{C}$. The following primary antibodies were used: chicken anti-GFP 1:800 (Abcam, catalog ab13970), mouse anti-AnkG 1:500 (UC Davis/NIH Neuromab, catalog clone N106/36 75146), rabbit anti-VGAT 1:3000 (Synaptic Systems catalog 131011), rabbit anti-ZsGreen 1:500 (Clonetech, catalog 632474), and rabbit anti-RFP 1:800 (Rockland, catalog 600-401-379). After three washing steps each $10 \mathrm{~min}$ in PBS, the slices were incubated in appropriate fluorescently labeled secondary antibodies in blocking reagent for visualization at room temperature for $2 \mathrm{~h}$. All secondary antibodies were purchased from Jackson ImmunoResearch. The following secondary antibodies were used at 
a concentration of $0.75 \mu \mathrm{g} / \mathrm{ml}$ : anti-chicken IgY Alexa Fluor 488 (catalog 703-545-155), anti-mouse IgG Alexa Fluor 488 (catalog 715-545-151), anti-rabbit IgG Alexa Fluor 488 (catalog 711-545-152), anti-rabbit IgG Cy3 (catalog 711-165-152), anti-mouse IgG Cy3 (catalog 715-165151), and anti-mouse IgG Cy5 (catalog 715-175-150). After four washing steps in PBS slices were mounted in FluoromountG mounting medium (Southern Biotech) and stored at $4^{\circ} \mathrm{C}$. Low-magnification fluorescent images were captured using a microscope (Olympus BX51, 4X UPlanSApo NA: 0.16; Olympus) equipped with a CCD camera (QImaging) and QCapture acquisition software. For detailed structural analysis, z-stack images were acquired using a confocal microscope [CLSM 780 or 880 (Zeiss), 20× Plan ApoChromat, NA: 0.8 (Zeiss), 63× Plan ApoChromat oil immersion, NA: 1.4 (Zeiss)]. For local analysis of axonal arbors, images were taken from the soma-containing slice. Three-dimensional reconstruction of axons included in a $100 \times 100 \mu \mathrm{m}$ square directly below the soma was semiautomatically performed using the filament tracer tool in the Imaris software followed by manual corrections. Because L2 ChCs analyzed in this study project dendrites mostly to L1, axonal areas barely overlap with dendritic branches. Indeed, our region of interest contained no dendritic structures. The total length of the axonal trajectory and the number of branch points defined as axonal bifurcation points were measured automatically using Imaris.

For quantification of AIS and off-target varicosities, the same images as used for axonal tracing were analyzed. The Imaris spots tool was used to automatically select varicosities: after automatic image thresholding, spots with diameter of smaller than $3 \mu \mathrm{m}$ in $x-y$ and $3.5 \mu \mathrm{m}$ in $z$ were selected as varicosities. The varicosities with the highest and the lowest intensity in each image were confirmed to meet the previously used criterion for axonal varicosities (De Paola et al., 2006) that they are at least two times brighter than the adjacent axonal shafts. AnkG signals representing AISs were 3D-rendered using the Imaris surface tool: after automatic thresholding of AnkG images, objects that have bounding boxes with larger than $10 \mu \mathrm{m}$ in height and $2 \mu \mathrm{m}$ in width were selected. The threshold value $(10 \times 2 \mu \mathrm{m})$ was determined based on the size of a bounding box for the smallest AIS stained with AnkG antibodies. Varicosities apposed to the rendered AISs were counted as AIS varicosities. The number of off-target varicosities was obtained by subtracting the number of AIS varicosities from the total number of varicosities.

Quantification of synaptophysin (Syp)-YFP and VGATpositive varicosities was manually performed using Fiji image analysis software. The background of Syp-YFP and VGAT images was determined by measuring the average intensity of putative cytosolic areas inside the somata. Puncta with mean gray values higher than the background level were considered Syp-YFP or VGAT signals. At least 50 varicosities per cell were analyzed for each type of varicosities (i.e., AIS and off-target varicosities) within a $100 \times 100 \mu \mathrm{m}$ square right below the soma.

\section{Immunoelectron microscopy (IEM)}

Mice were anesthetized with ketamine xylazine mixture (50 mg/kg ketamine, $5 \mathrm{mg} / \mathrm{kg}$ xylazine) and perfused transcardially with $0.9 \% \mathrm{NaCl}$ in $0.1 \mathrm{M}$ Sorensen's phosphate buffer (PB; $\mathrm{pH}$ 7.4) followed by $4 \%$ paraformaldehyde, $0.25-0.5 \%$ glutaraldehyde in $0.1 \mathrm{M} \mathrm{PB}$ for $12 \mathrm{~min} ; 50-\mu \mathrm{m}$ thick coronal sections of the cortex were obtained on a vibratome (Leica). GFP expressing single isolated ChCs were identified using an epi-fluorescence microscope [Olympus BX51 10× UPlanSApo NA: 0.4 (Olympus) or 20× UPlanFI NA: 0.5 (Olympus)] and slices containing single GFP expressing ChCs were selected for follow-up processing. After post-fixation in 4\% PFA in PB for $1 \mathrm{~h}$ and washing in $0.1 \mathrm{M} \mathrm{PB}$, sections were treated with $15 \%$ and $30 \%$ sucrose in $0.1 \mathrm{M}$ PB. Sections were permeabilized by submersion in liquid nitrogen followed by incubation in a blocking solution of $10 \%$ normal goat serum (NGS), $1 \%$ fish skin gelatin (FSG) in $50 \mathrm{mM}$ Tris buffered saline (TBS) for $1 \mathrm{~h}$. Sections were incubated with a rabbit anti-GFP antibody $(0.25 \mu \mathrm{g} / \mathrm{ml}$, Abcam, ab\#6556) diluted in TBS with $1 \%$ NGS, $0.1 \%$ FSG, washed with TBS and then incubated with a nanogold-conjugated anti-rabbit antibody (1:50, catalog 2003, Nanoprobe) diluted in TBS with $1 \%$ NGS, 0.1\% FSG. Immunogold-labeled sections were washed and silver enhanced using $\mathrm{HQ}$ Silver intensification kit (Nanoprobe, catalog 2012), then osmificated with $0.5 \% \mathrm{OsO}_{4}$, en bloc stained with $1 \%$ uranyl acetate, and dehydrated with a series of ethanol and acetone. Dehydrated sections were embedded in Fluka Durcupan resin (Sigma-Aldrich) and polymerized at $60^{\circ} \mathrm{C}$ for $2 \mathrm{~d}$. Immunogold-labeled ChCs were trimmed out under a dissecting scope and serially sectioned at $45-\mathrm{nm}$ thickness with an ultramicrotome (UC7, Leica). Serial ultrathin sections were counter stained with uranyl acetate and lead citrate. Samples were examined in a Tecnai G2 Spirit electron microscope (FEl) at $100 \mathrm{kV}$. Images were acquired with a Veleta CCD camera (Olympus) operated by TIA software (FEI).

\section{Transmission electron microscopy (TEM) data collection and analysis}

GFP-immunogold-positive profiles with a diameter over $200 \mathrm{~nm}$ were identified and those profiles were serially imaged to cover whole varicosities from neck to neck. A typical varicosity spans $13-19$ serial sections. TEM Image analysis was performed with Photoshop (Adobe) and Fiji image analysis software $(\mathrm{NIH})$. For $3 \mathrm{D}$ reconstruction the consecutive sections spanning one varicosity were aligned and the varicosity as well as the AIS structures were manually outlined. Subsequently, a 3D reconstruction image was automatically generated using Amira software (Amira 6.1.1, $\mathrm{FEI})$. Vesicles in the profiles were manually marked using Photoshop and counted. The same images were opened in Fiji and the area of profiles was demarcated with the polygon tool and measured. Immunogold particles in the profiles were thresholded and subtracted from the total area. To analyze the roundness of vesicles, all vesicles in the profiles were manually demarcated using the freehand tool and roundness was defined as $4 \pi *$ (area/perimeter $^{2}$ ) (Herman et al., 2014). 
Table 1. Statistical table

\begin{tabular}{|c|c|c|c|c|}
\hline & Data structure & Type of test & Power & Experiments \\
\hline a & Normal distribution & One-way ANOVA Bonferroni post hoc & $p=0.0043$ & Mean number of branch points \\
\hline $\mathrm{b}$ & Normal distribution & One-way ANOVA Bonferroni post hoc & $p=0.0003$ & Mean number of total varicosities \\
\hline C & Normal distribution & One-way ANOVA Bonferroni post hoc & $p=0.0001$ & Mean number of off-target varicosities \\
\hline d & Normal distribution & One-way ANOVA Bonferroni post hoc & $p=0.0001$ & Mean number of AIS varicosities \\
\hline e & Normal distribution & Student's $t$ test, two tailed, unpaired & $p=0.542$ & Mean number of varicosities/AIS \\
\hline$f$ & Normal distribution & Student's $t$ test, two tailed, unpaired & $p=0.244$ & Mean number of cartridges \\
\hline g & Normal distribution & One-way ANOVA Bonferroni post hoc & $p<0.0001$ & Mean \% of off-target varicosities \\
\hline $\mathrm{h}$ & Normal distribution & Student's $t$ test, two tailed, unpaired & $p<0.0001$ & Mean $\%$ of VGAT+ varicosities P16 \\
\hline $\mathrm{i}$ & Normal distribution & Student's $t$ test, two tailed, unpaired & $p=0.0191$ & Mean number of branch points (transpl.) \\
\hline j & Normal distribution & Student's $t$ test, two tailed, unpaired & $p=0.0238$ & Mean number of total varicosities (transpl.) \\
\hline $\mathrm{k}$ & Normal distribution & Student's $t$ test, two tailed, unpaired & $p<0.0001$ & Mean \% of off-target varicosities (transpl.) \\
\hline I & Normal distribution & Student's $t$ test, two tailed, unpaired & $p<0.0001$ & Mean \% of Syp + varicosities \\
\hline $\mathrm{m}$ & Normal distribution & One-way ANOVA Bonferroni post hoc & $p=0.0002$ & Mean density of vesicles P16 \\
\hline $\mathrm{n}$ & Normal distribution & One-way ANOVA Bonferroni post hoc & $p<0.0001$ & Mean roundness of vesicles P16 \\
\hline 0 & Normal distribution & Student's $t$ test, two tailed, unpaired & $p<0.0001$ & Mean \% of VGAT+ varicosities P28 \\
\hline $\mathrm{p}$ & Normal distribution & Student's $t$ test, two tailed, unpaired & $p=0.78$ & Mean density of vesicles P28 \\
\hline q & Normal distribution & Student's $t$ test, two tailed, unpaired & $p<0.0001$ & Mean roundness of vesicles P28 \\
\hline
\end{tabular}

\section{Statistical analyses}

Data are presented as the mean \pm SEM throughout experiments. All data were collected from at least three independent experiments or animals. All statistical analyses were performed using Prism 6. Normality of the data were assessed by the Shapiro-Wilk test. Differences were tested using Student's $t$ test for two groups or one-way ANOVA for more than two groups. After ANOVA a Bonferroni post hoc test was performed to analyze statistical significance between groups; $p<0.05$ was considered significant. Statistical significance was presented in figures and throughout the text in the following manner: $* p<0.05, * * p<0.01$, and $* * * p<0.001$. A summary of each statistical analysis can be found in Table 1.

\section{Results}

\section{Axonal branches and varicosities are concurrently increased and pruned in developing $\mathrm{ChCs}$}

To characterize the developmental processes of $\mathrm{ChC}$ axonal branching and synapse organization, we labeled cortical ChCs by combining Nkx2.1-CreER knockin mice with loxP-stop-loxP-RFP (LSL-RFP) reporter mice (Fig. 1B; Madisen et al., 2010; Taniguchi et al., 2011; Taniguchi et al., 2013). RFP induction in MGE progenitors at E17 predominantly labels cortical ChCs in postnatal Nkx2.1CreER;LSL-RFP mice (Fig. 1A-C; Madisen et al., 2010; Taniguchi et al., 2013). Since labeled ChCs were most frequently found in the upper sublayer of $L 2$ facing $L 1$ in the MPFC and ACC, we focused on L2 ChCs in these cortical areas. To visualize axonal structures at high resolution, we optimized the dose of $\operatorname{Tmx}$ to a point where we could reliably label ChCs that were clearly separated from each other (Fig. 1C-F). Our analysis focused on branch points and varicosities, which have been used as metrics for branching and synaptogenesis, respectively.

By P7, ChCs developed one or two long and less branched vertical processes projecting toward deeper layers; they also formed several short processes from the soma, extending into L1 (Fig. 1G, P7, yellow arrows). By $\mathrm{P} 12$, ChCs began to exhibit intertwined and curved axonal processes (Fig. 1G, P12). Several horizontal axonal collaterals bilaterally emanated from a primary axon, forming multidirectional, dense, and complex branches into deeper layers (Fig. 1G, P12, arrows). At this stage, they developed only a limited number of prominent putative cartridges (Fig. $1 G, \mathrm{P} 12$, arrowheads). By P16, the size and complexity of $\mathrm{ChC}$ axonal arbors dramatically increased, and several axonal collaterals frequently extended horizontally (Fig. 1G, P16, arrows). Many putative cartridges (Fig. 1G, P16, arrowheads) emerged but were difficult to isolate because of numerous varicosities between them. After P21, ChCs displayed a mature axonal organization, which was characterized by regularly spaced vertical branches with prominent putative cartridges (Fig. 1G, P28, arrowheads). The exuberant varicosities between putative cartridges found at P16 appeared to be pruned by this stage.

To validate these qualitative observations, we conducted quantitative analyses of axonal arbors at P12, P16, P21, and P28 with the aid of the image analysis software Imaris. Three-dimensional images of proximal axonal arbors in a $100 \times 100 \mu \mathrm{m}$ square located immediately below the soma were reconstructed from $z$-stacked confocal images and skeletonized for measurement (Fig. 2A,B; Movie 1). We counted the number of branch points and varicosities. We found that both values significantly increased between $\mathrm{P} 12$ and P16 and decreased between P16 and P28 (Fig. $2 C, D$; mean number of branch points ${ }^{\mathrm{a}}$ : $\mathrm{P} 12,137 \pm 14$; $\mathrm{P} 16,290 \pm 37$; P21, $171 \pm 26$; P28, $102 \pm 8$; mean number of varicosities ${ }^{\text {b }}$ : P12, $167 \pm 16$; P16, $263 \pm 14$; $\mathrm{P} 21,200 \pm 17 ; \mathrm{P} 28,188 \pm 10 ; n=10 \mathrm{ChCs}$ for each time point; one-way ANOVA: $* p<0.05, * * p<0.01, * * * p<$ $0.001, * * * * p<0.0001)$. These results identify a developmental time course of axonal arborization followed by pruning in developing ChCs. They also suggest that branches and varicosities of ChCs are concurrently augmented and remodeled during the second and third postnatal weeks, respectively. 


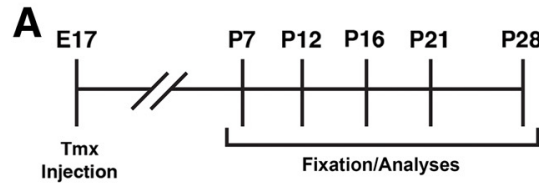

B

Nkx2.1-CreER;LSL-RFP (ChC)
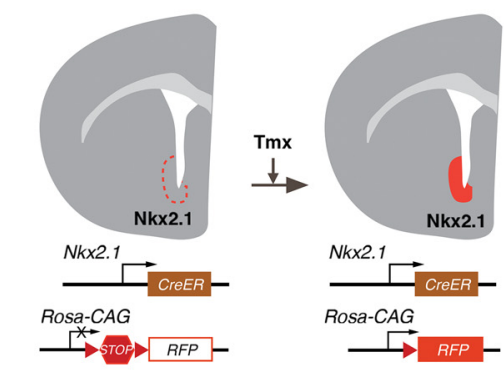
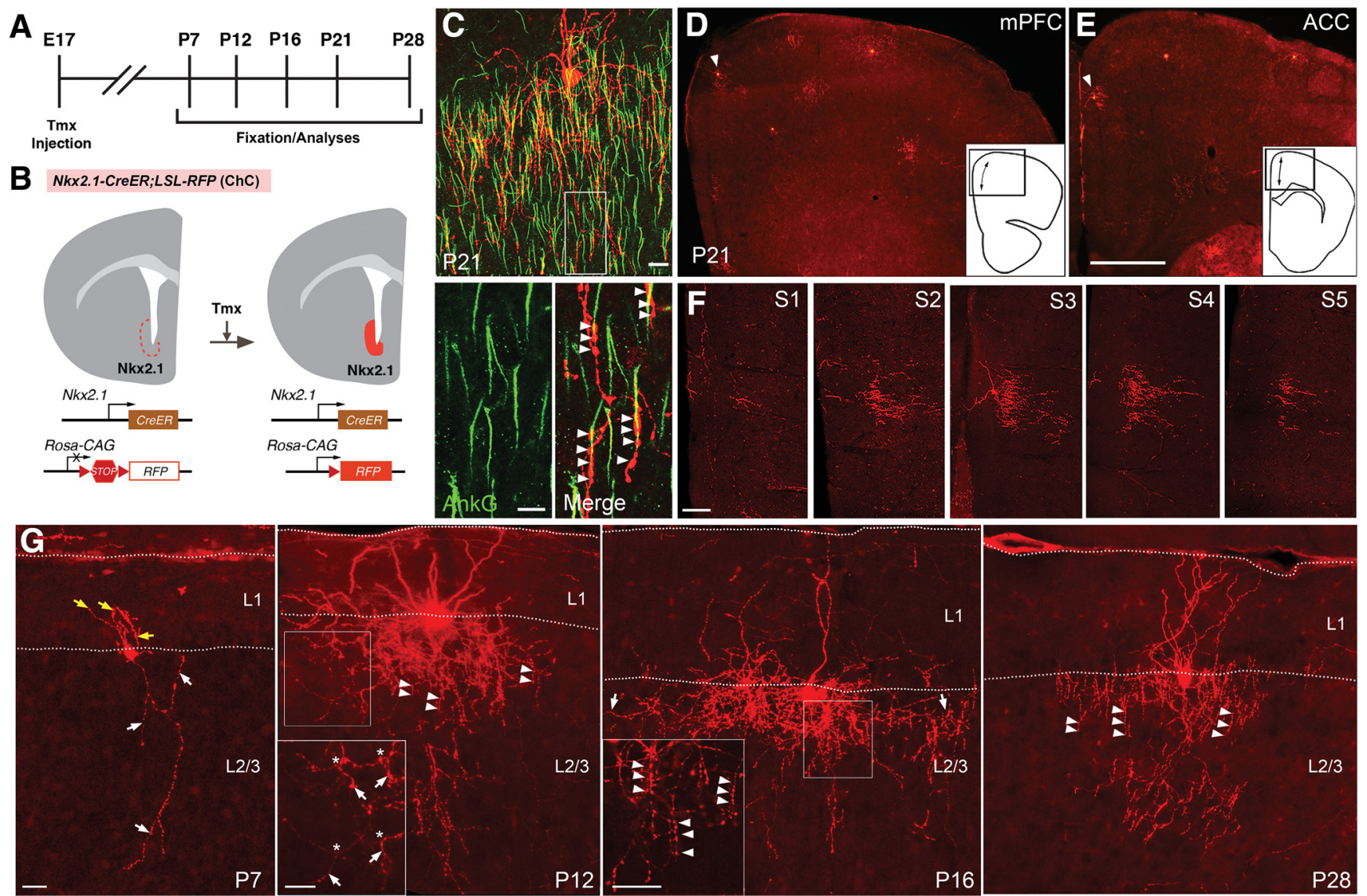

Figure 1. $\mathrm{ChC}$ axonal branches and varicosities undergo developmental refinement. $\boldsymbol{A}$, Experimental timeline. Timed pregnant females were administered with Tmx at E17 to induce Cre activity in Nkx2.1-CreER;LSL-RFP embryos. Pups were analyzed at each indicated postnatal time point. $\boldsymbol{B}$, Upper schematics show coronal sections in a late embryonic Nkx2.1-CreER;LSL-RFP brain depicting induction of RFP in the Nkx2.1-expressing MGE. Lower schematics denote Tmx-induced excision of a STOP cassette resulting in constitutive RFP expression. $\boldsymbol{C}$, top panel, A confocal projection image of a P21 L2 ChC (red) and AISs labeled by AnkG staining (green). Bottom panels, High-magnification confocal images of a single optical section in a boxed area in top panel. Note putative cartridges (arrowheads) associated with AISs. Scale bars, $20 \mu \mathrm{m}$ (top) and $10 \mu \mathrm{m}$ (bottom). $\boldsymbol{D}$, E, Epifluorescent images of partial coronal sections containing the mPFC $(\boldsymbol{D})$ and the ACC $(\boldsymbol{E})$ of a P21 brain induced by low-dose Tmx at E17. Note that RFP+ cells (arrowheads) are sparsely labeled. Schematics in insets show whole coronal sections at the level of the mPFC and the ACC in $\boldsymbol{D}, \boldsymbol{E}$, respectively. The double-headed arrows show areas of the mPFC and the ACC in $\boldsymbol{D}, \boldsymbol{E}$, respectively. Scale bar, $200 \mu \mathrm{m}$. $\boldsymbol{F}$, Confocal projection images of five serial $60-\mu \mathrm{m}$ sections spanning a whole single L2 ChC in a P21 brain induced at E17. Note that there is no overlap with other cells. Scale bar, $100 \mu \mathrm{m}$. G, Confocal projection images of single ChCs at P7, P12, P16, and P28. White and yellow arrows in P7 show axons and presumptive immature dendrites extending downwards and upwards, respectively. Insets in P12 and P16 show confocal images of single optical sections in boxed areas. Arrowheads in the P12, P16, and P21 image indicate putative cartridges. Asterisks in a P12 ChC image denote branch points at which horizontal axons form vertical branches downward (arrows). Arrows in a P16 ChC image show axonal collaterals. Scale bars, 25 and $20 \mu \mathrm{m}$ (insets).

\section{Developing ChCs form AIS and off-target varicosities that undergo distinct developmental regulation}

The numerous varicosities formed by younger ChCs (e.g., P12 and P16) make putative cartridges difficult to isolate (Fig. 1G, P12 and P16). This observation led to our hypothesis that young ChCs form varicosities that are not associated with AISs. To test this hypothesis, we labeled AISs with anti-AnkG antibodies, which unambiguously label AISs and enable the identification of cartridges in ChCs (Fig. 1C). We confirmed the reliability of our immunohistochemistry-based detection of AISs by staining brain sections containing PNs electroporated with GFP; we detected AISs of all the GFP-expressing PNs (data not shown). Interestingly, our analysis revealed that P12 ChCs formed many off-target varicosities in addition to AIS varicosities (Fig. $3 A$ ); in fact, off-target varicosities outnumbered AIS varicosities at P12 (Fig. 3E).

To characterize the developmental dynamics of offtarget and AIS varicosities, we examined their average number along proximal axonal arbors at different time points (Fig. 1A). Off-target and AIS varicosities concurrently increased between P12 and P16 (Fig. 3C,D; mean number of off-target varicosities ${ }^{\mathrm{C}}$ : P12, $101 \pm 14$; P16, $155 \pm 11$; mean number of AIS varicosities ${ }^{\mathrm{d}}: \mathrm{P} 12,66 \pm 5$; $\mathrm{P} 16,109 \pm 5 ; n=10 \mathrm{ChCs}$ for each time point; one-way ANOVA: $* * p<0.01, * * * p<0.001)$. However, off-target varicosities markedly decreased by half between $\mathrm{P} 16$ and P21 (Fig. 3C; mean number of off-target varicosities ${ }^{c}$ : 

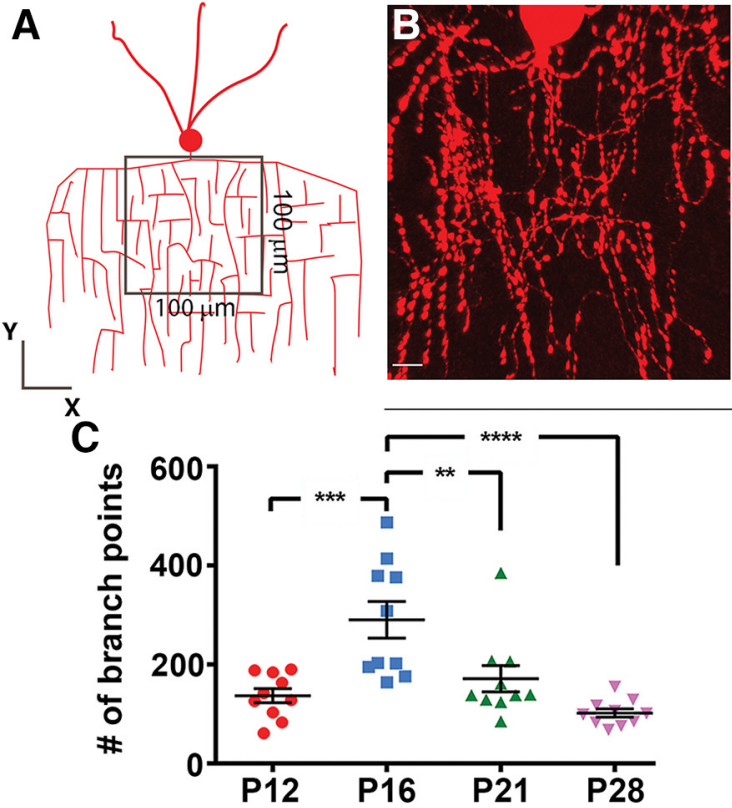

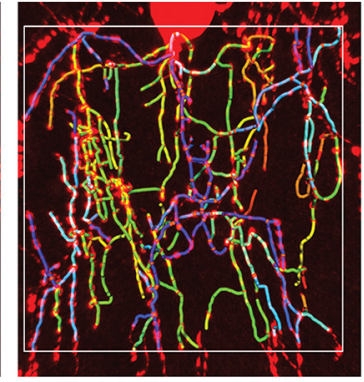

Skeletonize axonal arbors

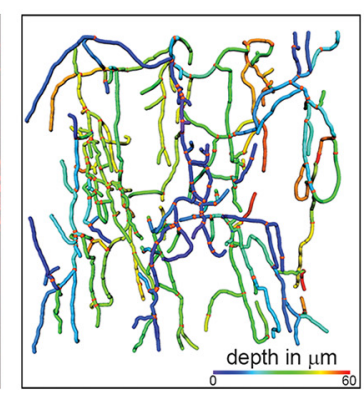

D

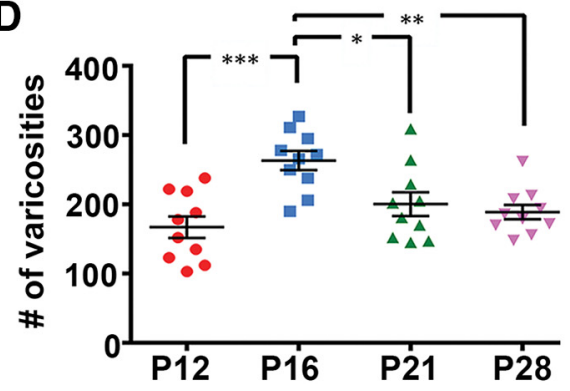

Figure 2. Quantitative analyses of branch points and varicosities during postnatal development. A, B, A strategy for quantification of ChC axonal arbors. A schematic showing a square area $(100 \times 100 \mu \mathrm{m})$ selected for axonal arbor analysis in a 60- $\mu \mathrm{m}$-thick section containing a ChC. The square was placed directly below a soma. Three-dimensional images were reconstructed from z-stacked confocal images within the square, axonal trajectories were semiautomatically traced using Imaris with manual corrections, and axonal branches are color-coded according to their depth (B). See also Movie 1. $\boldsymbol{C}$, The average number of branch points in ChCs at different postnatal ages. The number of branch points at P16 is significantly greater than those at P12, P21, and P28 ( $n=10$ ChCs for each; $\geq 3$ brains per condition; one-way ANOVA: $* * p<0.01$, $* * * p<0.001$, ****p $<0.0001)^{a}$. Data are presented as mean \pm SEM. $\boldsymbol{D}$, The average total number of ChC axonal varicosities. The total number of varicosities at P16 is significantly greater than those at P12, P21, and P28 $(n=10 \mathrm{ChCs}$ for each; $\geq 3$ brains per condition; one-way ANOVA: $* p<0.05, * * p<0.01, * * * p<0.001)^{\mathrm{b}}$. Data are presented as mean \pm SEM.

$\mathrm{P} 16,155 \pm 11 ; \mathrm{P} 21,92 \pm 12 ; n=10 \mathrm{ChCs}$ for each time point; one-way ANOVA: $* * p<0.01$ ), whereas the average number of AIS varicosities remained at the same level from P16 onward (Fig. 3D; mean number of AIS varicosities $^{\mathrm{d}}$ : P16, $109 \pm 5 ; \mathrm{P} 21,109 \pm 7 ; \mathrm{P} 28,107 \pm 10 ; n=10$ ChCs for each time point; one-way ANOVA: $p>0.05$ ). The average number of varicosities per AIS and the average number of cartridges did not change between P16 and P21 (mean number of varicosities per AIS ${ }^{\mathrm{e}}$ : P16, 4.9

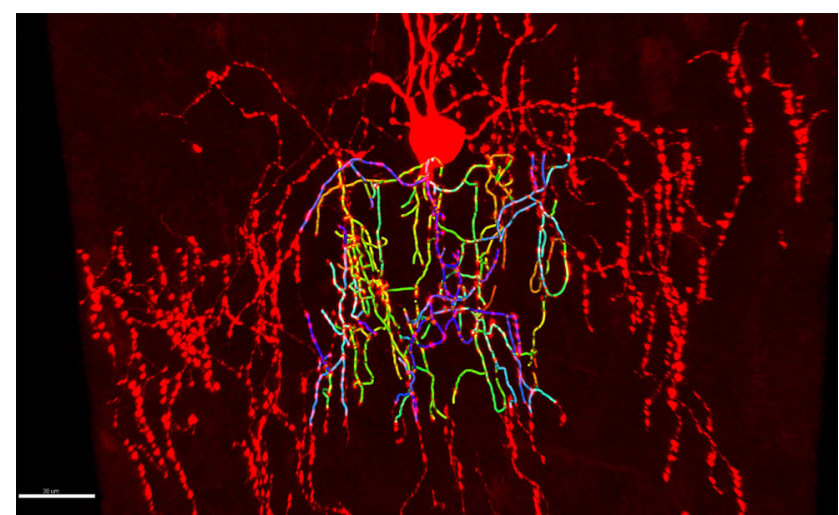

Movie 1. Axonal tracing of cortical ChCs. Three-dimensional reconstruction of $60-\mu \mathrm{m}$ confocal z-stack of a ChC whose axonal arbor in a $100 \times 100 \mu \mathrm{m}$ square below the soma was traced using Imaris software. $\pm 0.1 ; \mathrm{P} 21,5.2 \pm 0.1 ;$ Student's $t$ test: $p=0.542 ;$ mean number of cartridges: P16, $29 \pm 2$; P21, $27 \pm 2$; Student's $t$ test: $p=0.244 ; n=10$ ChCs for each time point; P16: 292 cartridges, 1438 varicosities; P21: 271 cartridges, 1407 varicosities), suggesting that the formation of AIS varicosities is complete as early as P16 at least in proximal $\mathrm{ChC}$ axons.

Overall, these results define the developmental time frame during which $\mathrm{ChC}$ axons establish varicosities that are associated with AISs and exhibit the vertically elongated appearance of cartridges. They further demonstrate that developmental remodeling of varicosities is due to specific pruning of off-target varicosities that are excessively generated during axonal elaboration. It is of note that off-target varicosities occupy a significant fraction of total varicosities at least in young adult animals (e.g., P21 and P28; Fig. 3B,C,E; mean percentage of off-target varicosities $^{9}$ : P12, $59 \pm 3 \%$; P16, $58 \pm 1 \%$; P21, $45 \pm 2 \%$; $\mathrm{P} 28,44 \pm 3 \% ; n=10 \mathrm{ChCs}$ for each time point; one-way ANOVA: $* * p<0.01$ ).

\section{Developing ChCs form synapses at AIS but not off- target varicosities}

Although axonal varicosities have been appreciated as structural indicators for presynaptic terminals (Chattopadhyaya et al., 2004; Ruthazer et al., 2006; Chattopadhyaya et al., 2007; Wu et al., 2012), nonsynaptic varicosities have also been found in transverse branches of climbing fibers in the adult cerebellum (Nishiyama et al., 2007). 

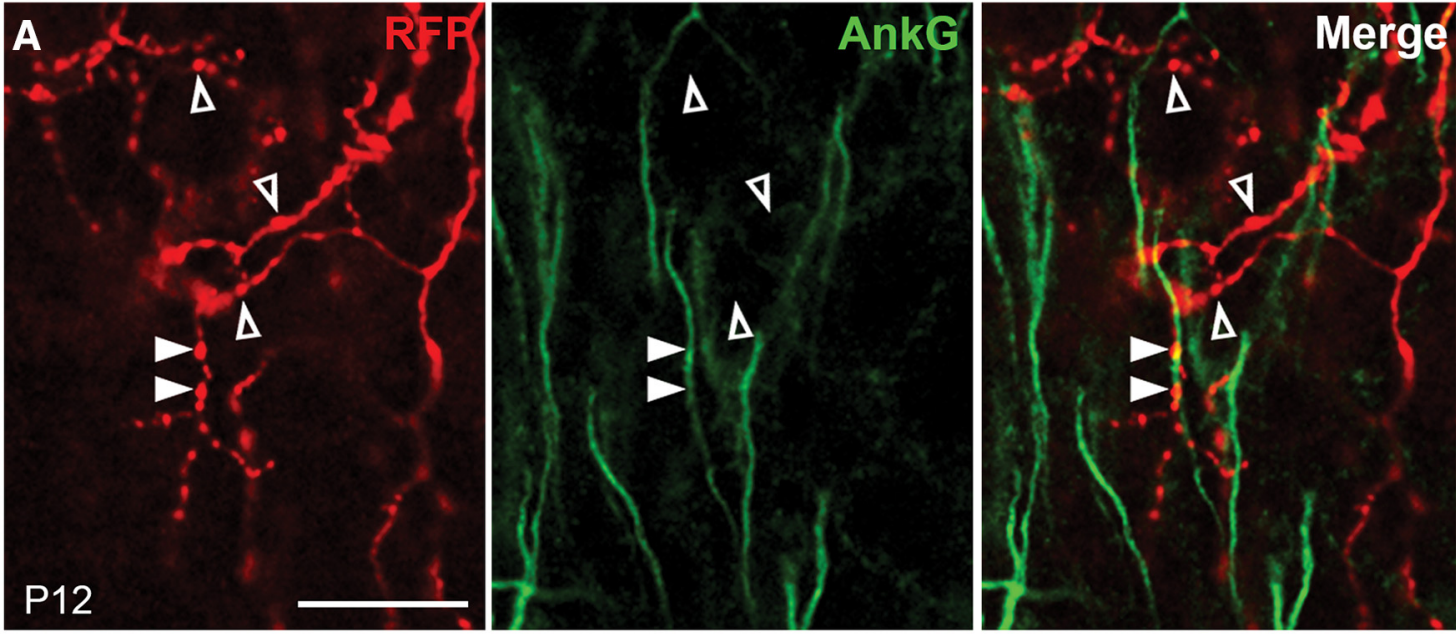

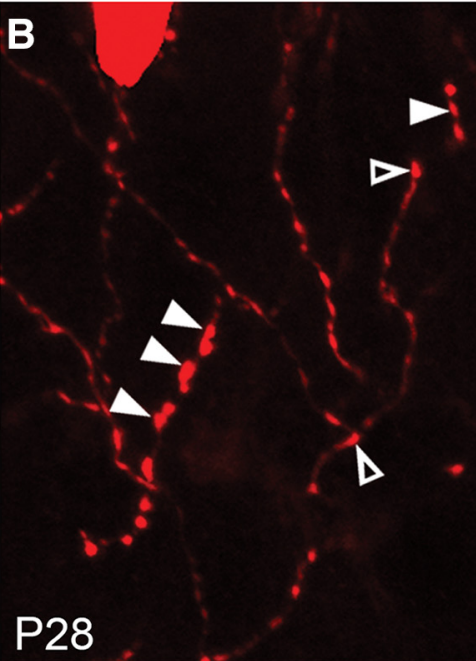

C Off-target varicosities

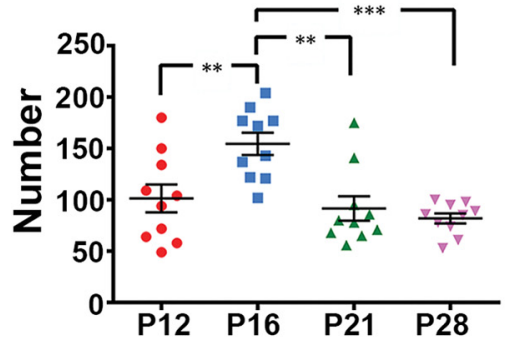

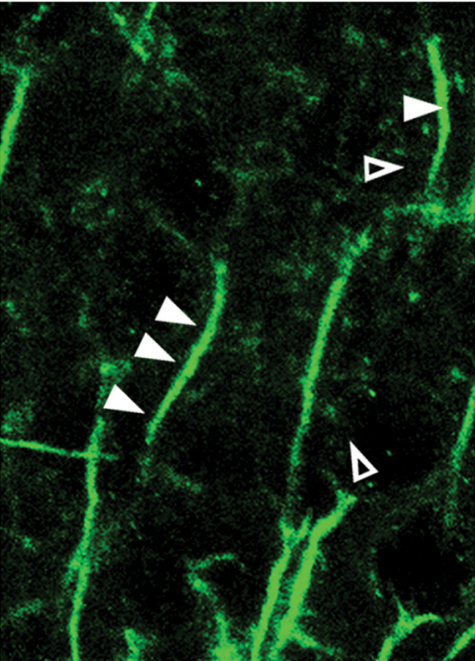
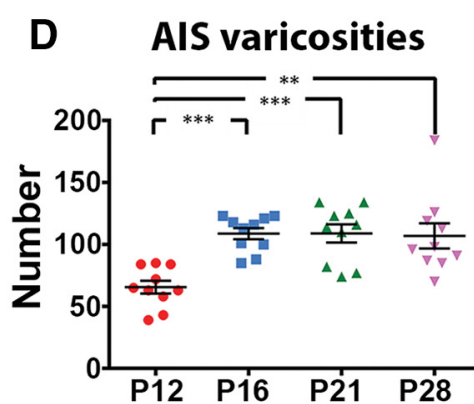

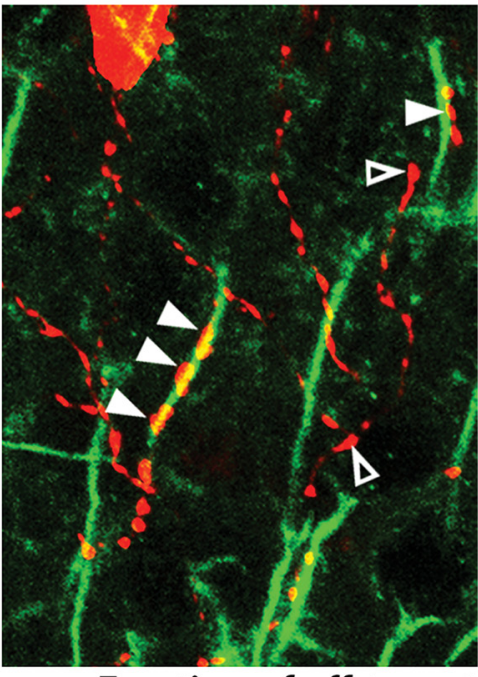

E Fraction of off-target varicosities

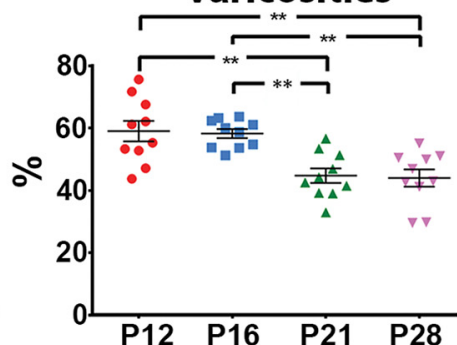

Figure 3. ChCs form AIS and off-target varicosities that undergo distinct developmental regulation. $\boldsymbol{A}, \boldsymbol{B}$, Confocal images of single optical sections showing varicosities (red) and AISs labeled by AnkG staining (green) in P12 (A) and P28 (B) brains. Filled and empty arrowheads represent AIS and off-target varicosities, respectively. Scale bar, $20 \mu \mathrm{m}$. See also the Movie 1. C , The average number of off-target varicosities. The number of off-target varicosities at P16 is significantly greater than those at P12, P21, and P28 $(n=10$ ChCs for each; $\geq 3$ brains per condition; one-way ANOVA: $* * p<0.01$, $* * * p<0.001)^{c}$. Data are presented as mean \pm SEM. $\boldsymbol{D}$, The average number of AIS varicosities. The number of AIS varicosities at P12 is significantly lower than those at P16, P21, and P28 ( $n$ $=10$ ChCs for each; $\geq 3$ brains per condition; one-way ANOVA: $* * p<0.01, * * * p<0.001)^{\mathrm{d}}$. Data are presented as mean \pm SEM. $\boldsymbol{E}$, The average percentage of off-target varicosities. The percentage of off-target varicosities at P21 and at P28 is significantly greater than those at P12 and P16 $(n=10 \mathrm{ChCs} \text { for each; } \geq 3 \text { brains per condition; one-way ANOVA: } * * p<0.01)^{\mathrm{g}}$. Data are presented as mean \pm SEM.

To determine whether synapses are formed exclusively at AIS varicosities or ubiquitously at both AIS and offtarget varicosities during the wiring of $\mathrm{ChC}$ axons, we first conducted immunohistochemistry with antibodies against vesicular GABA transporter (VGAT), a marker for GABAergic synaptic vesicles, and AnkG in P16 Nkx2.1-CreER; LSL-tGFP mice (Fig. 4A). We found that a significantly higher percentage of AIS varicosities contain VGAT com- 

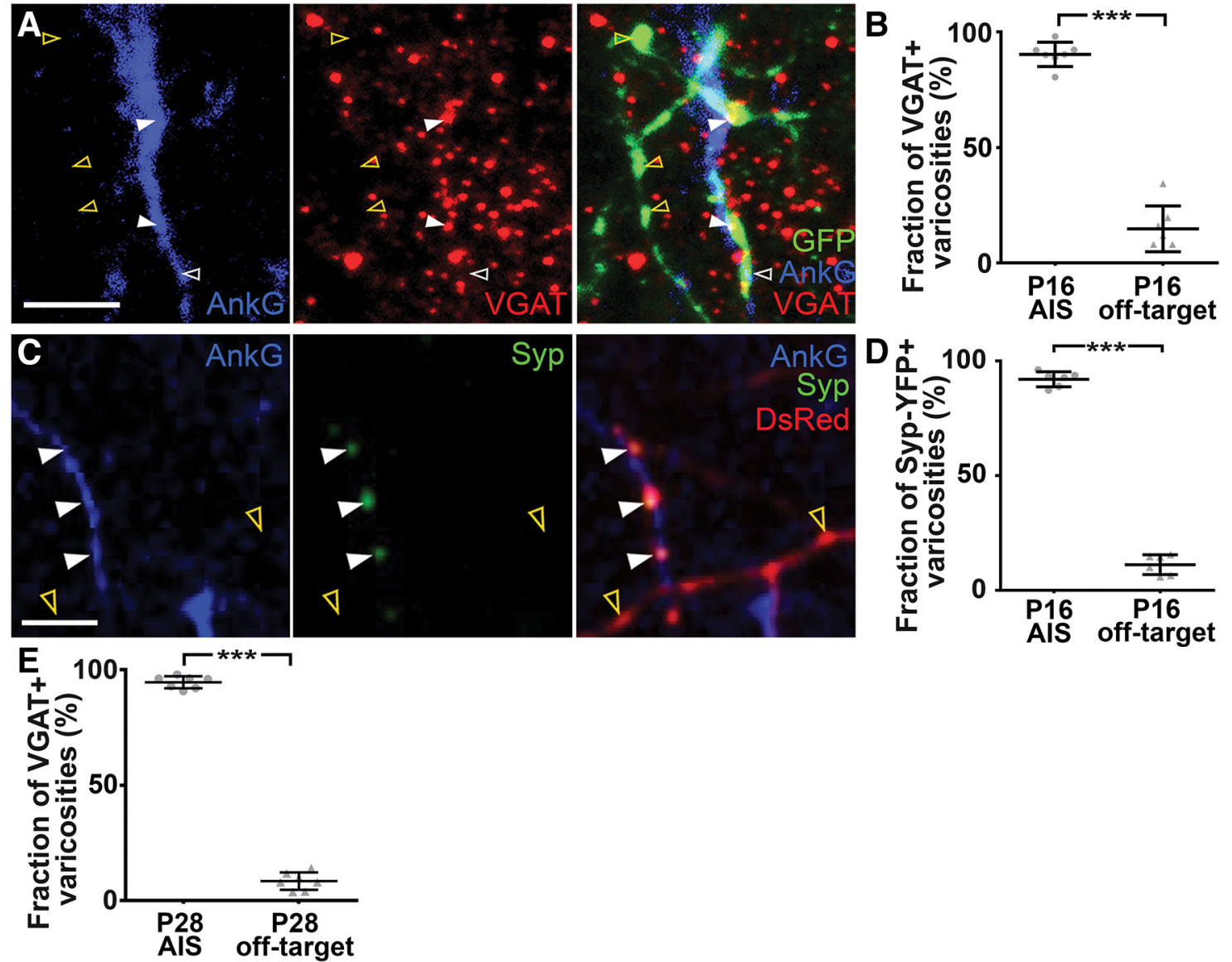

Figure 4. AIS but not off-target varicosities predominantly contain presynaptic markers. $\boldsymbol{A}$, Immunohistochemical analysis of VGAT localization in ChC varicosities in Nkx2.1-CreER;LSL-tGFP mice. Confocal images of a single optical section showing varicosities (green), VGAT (red), and AISs visualized by AnkG immunostaining (blue) in a P16 brain. White and yellow arrowheads indicate AIS and off-target varicosities, respectively. Filled and empty arrowheads show VGAT+ and VGAT- varicosities in ChC axons, respectively. Scale bar, $5 \mu \mathrm{m}$. B. The average percentage of VGAT-containing AIS and off-target varicosities in P16 ChCs. The percentage of VGAT-containing AIS varicosities is significantly higher than that of VGAT-containing off-target varicosities $(n=7 \mathrm{ChCs}$ for each; $\geq 3$ brains per condition; Student's $t$ test: $* * p<0.001)^{\mathrm{h}}$. Data are presented as mean \pm SEM. $\boldsymbol{C}$, Localization of Syp-YFP puncta in varicosities of transplanted ChCs. Confocal images of a single optical section showing AIS visualized by AnkG immunostaining (blue), Syp-YFP (green), and varicosities along the axon (red) in an EP16 brain. White and yellow arrowheads indicate AIS and off-target varicosities, respectively. Filled and empty arrowheads show Syp-YFP+ and Syp-YFP- varicosities in ChC axons, respectively. Scale bar, $5 \mu \mathrm{m}$. $\boldsymbol{D}$, The average percentage of Syp-YFP-containing AIS and off-target varicosities in EP16 ChCs. The percentage of Syp-YFP containing AIS varicosities is significantly higher than that of Syp-YFP containing off-target varicosities $(n=6$ ChCs; $\geq 3$ brains; Student's $t$ test: $* * * p<0.001)^{\prime}$. Data are presented as mean \pm SEM. $\boldsymbol{E}$, The average percentage of VGAT-containing AIS and off-target varicosities in P28 ChCs. The percentage of VGAT-containing AIS varicosities is significantly higher than that of VGATcontaining off-target varicosities $(n=7 \mathrm{ChCs} \text { for each; } \geq 3 \text { brains per condition; Student's } t \text { test: } * * * p<0.001)^{\circ}$. Data are presented as mean \pm SEM. See Extended Data Figure 4-1.

pared with off-target varicosities (Fig. 4A,B; mean percentage of VGAT-positive varicosities at P16 : AIS, $90 \pm$ $2 \%$; off-target, $15 \pm 4 \% ; n=7$ ChCs, 357 AlS varicosities, 356 off-target varicosities; Student's $t$ test: $* * * p<$ $0.001)$, supporting the view that developing ChCs predominantly form synapses at AIS varicosities.

To further validate the predominant localization of synaptic markers in AIS varicosities at high resolution, we cotransfected ex vivo ChC progenitors with Syp-YFP and DsRed and transplanted them into the SSC of P1 host animals (Figs. 4C, Fig. 4-1A). This approach allowed us to express genes of interest in ChCs more reliably and efficiently than in utero electroporation, with which it is hard to target $\mathrm{ChC}$ progenitors localized in the small, ventral- most domain of the subpallial ventricular/subventricular zone at late embryonic stages (e.g., E16 and E17). We confirmed that donor ChCs developed roughly $3 \mathrm{~d}$ later than host ChCs. For example, transplanted ChCs in P19 host mice were equivalent to endogenous P16 (EP16) ChCs (Fig. 4-1). They underwent normal developmental processes with a time course similar to endogenous $\mathrm{ChCs}$ (Fig. 4-1). In EP16 ChCs, a significantly higher fraction of AIS varicosities contained Syp-YFP compared with offtarget varicosities (Fig. 4C,D; mean percentage of SypYFP-positive varicosities at EP16': AIS-varicosities, $92 \pm$ $1 \%$; off-target varicosities, $12 \pm 2 \% ; n=6$ ChCs, 464 AIS varicosities, 446 off-target varicosities; Student's $t$ test: $* * * p<0.001)$, validating the idea that developing ChCs 
specifically form synapses at AIS but not off-target varicosities.

To further characterize off-target and AIS varicosities at an ultrastructural level, we performed serial section IEM analyses in Nkx2.1-CreER;LSL-tGFP mice at P16. We defined varicosities as axonal swellings $>200 \mathrm{~nm}$ in diameter. To precisely characterize ultrastructural features of individual varicosities, we obtained 3D profiles through reconstruction of successive ultrathin sections (Fig. 5A,B, right panels). We identified AISs by their electron-dense membranous structures of the axon (Fig. 5A, white arrows; Palay et al., 1968) and considered varicosities as synaptic when they showed a parallel apposition of symmetric electron density with accumulation of synaptic vesicles (Fig. 5A,C, blue arrowheads).

As expected, we found two types of varicosities: AIS and off-target. The majority of AIS varicosities possessed clear symmetric synapses on AISs with synaptic vesicles that were of a typical GABAergic jellybean shape (Angaut and Sotelo, 1989; Fig. 5A,C; percentage of synaptic varicosities: AIS, $71 \%, n=21$ varicosities). In contrast, off-target varicosities were not associated with the AIS (Fig. 5B,D), and the structures with which they were associated were neuropil, not AISs and somata. Unlike AIS synaptic varicosities, off-target varicosities showed no sign of synapses but contained many round vesicles (Fig. $5 B, D$; percentage of synaptic varicosities: off-target, $0 \%$, $n=9$ varicosities). Notably, more than half of varicosities along $\mathrm{ChC}$ axons contained mitochondria (Fig. $5 D$, yellow asterisk; percentage of varicosities containing mitochondria: AIS synaptic varicosities, $66.7 \%, n=15$ varicosities; off-target varicosities, $55.6 \%, n=9$ varicosities), regardless of their type, suggesting that they are not artificial structures generated during sample preparation.

To rule out the possibility that off-target, nonsynaptic varicosities were observed because of uneven detection of AISs and/or synapses, we performed quantitative morphologic analyses of vesicles in varicosities. Specifically, we quantified vesicle density and roundness in AIS and off-target varicosities. AIS-synaptic varicosities showed significantly higher density of vesicles compared with off-target varicosities at P16 (Fig. 5C,D,F; mean density of synaptic vesicles at $\mathrm{P} 16^{\mathrm{m}}$ : AIS, $101 \pm 9 / \mu \mathrm{m}^{2}, n=15$ varicosities; off-target, $44 \pm 6 / \mu \mathrm{m}^{2}, n=9$ varicosities; Student's $t$ test: $* * * p<0.001)$. To analyze roundness, we included vesicles in excitatory presynaptic terminals as a control because they represent a round morphology (Fig. $5 E$, red arrows), which is in contrast to jellybean-like GABAergic vesicles. Our quantification indicated that excitatory vesicles have the highest roundness, followed by off-target and AIS varicosities (Fig. $5 C-E, H$; mean roundness at P16n: excitatory presynapse, $0.893 \pm 0.001, n=$ 29 presynaptic terminals, 117 vesicles; off-target, $0.82 \pm$ $0.01, n=9$ varicosities, 157 vesicles; AIS, $0.75 \pm 0.01, n$ $=15$ varicosities, 375 vesicles; one-way ANOVA: $* * * p<$ $0.001)$. These quantitative morphologic data suggest that AIS and off-target varicosities have distinct ultrastructural features, negating the possibility that they are artificially classified due to ambiguous identifications of AISs and synaptic specializations on IEM. Taken together, these results suggest that although developing ChCs form AIS and off-target varicosities, synapses are specifically formed at AIS varicosities.

\section{ChCs maintain synapse specificity in young adulthood}

As described above, a significant number of off-target varicosities remain into young adulthood (e.g., P21 and P28). One could argue that they mature into synapses by early adult stages. To test this possibility, we examined synaptic properties of axonal varicosities at P28 by immunohistochemistry with VGAT antibodies and IEM analyses.

Similarly to P16 ChCs, $<10 \%$ of off-target varicosities exhibited VGAT signals while $94 \%$ of AIS varicosities did so (Fig. 4E; mean percentage of VGAT-positive varicosities at P28: AIS, $95 \pm 1 \%$; off-target, $9 \pm 1 \% ; n=7$ ChCs, 398 AIS varicosities, 353 off-target varicosities; Student's $t$ test: $* * * p<0.001)$. Consistent with this result from a light microscopic analysis, our IEM analyses demonstrated that AIS but not off-target varicosities possess synaptic features defined by accumulation of synaptic vesicles near plasma membranes and a cleft flanked with parallel electron dense membranes (percentage of synaptic varicosities at P28: AIS $100 \%, n=24$ varicosities; off-target, $0 \%, n=5$ varicosities). Although we found no difference in the density of vesicles in AIS and off-target varicosities at P28 (Fig. 5G; mean density of synaptic vesicles at P28 ${ }^{\mathrm{P}}$ : AIS, $105 \pm 5 / \mu \mathrm{m}^{2}, n=24$ varicosities; off-target, $102 \pm 13 / \mu \mathrm{m}^{2}, n=5$ varicosities; Student's $t$ test: n.s. $p=0.78$ ), the vesicle morphology was still significantly different between AIS and off-target varicosities (Fig. 5/; mean roundness at P28q: AIS, $0.758 \pm 0.003$, $n=24$ varicosities, 661 vesicles; off-target, $0.81 \pm 0.02$, $n=5$ varicosities, 116 vesicles; Student's $t$ test: $* * * p<$ 0.001). Taken together, these results suggest that synapse specificity of ChCs persists from early postnatal development to at least young adulthood.

\section{Discussion}

Structured branching in target areas and subcellular synapse specificity are the most striking anatomic features of IN axons (Somogyi et al., 1998; Karube et al., 2004; Huang et al., 2007; Jiang et al., 2015). However, it has been unclear whether axonal organization and synaptic specificity of cortical INs are predetermined or established after refinement. Addressing these questions has been hampered by difficulties in tracking the development of homogenous IN subtypes with single-cell resolution. Here, by genetically targeting $\mathrm{ChC}$ progenitors, we established that developing ChCs form excessive branches and varicosities that eventually undergo pruning. Furthermore, we found that although ChCs form offtarget varicosities as well as AIS varicosities, synapses are selectively formed at AIS varicosities during development and this synapse specificity persists into young adulthood. Our results provide evidence that ChCs establish subcellular synapse specificity in a predetermined manner while shaping axonal arbors through branch remodeling. 

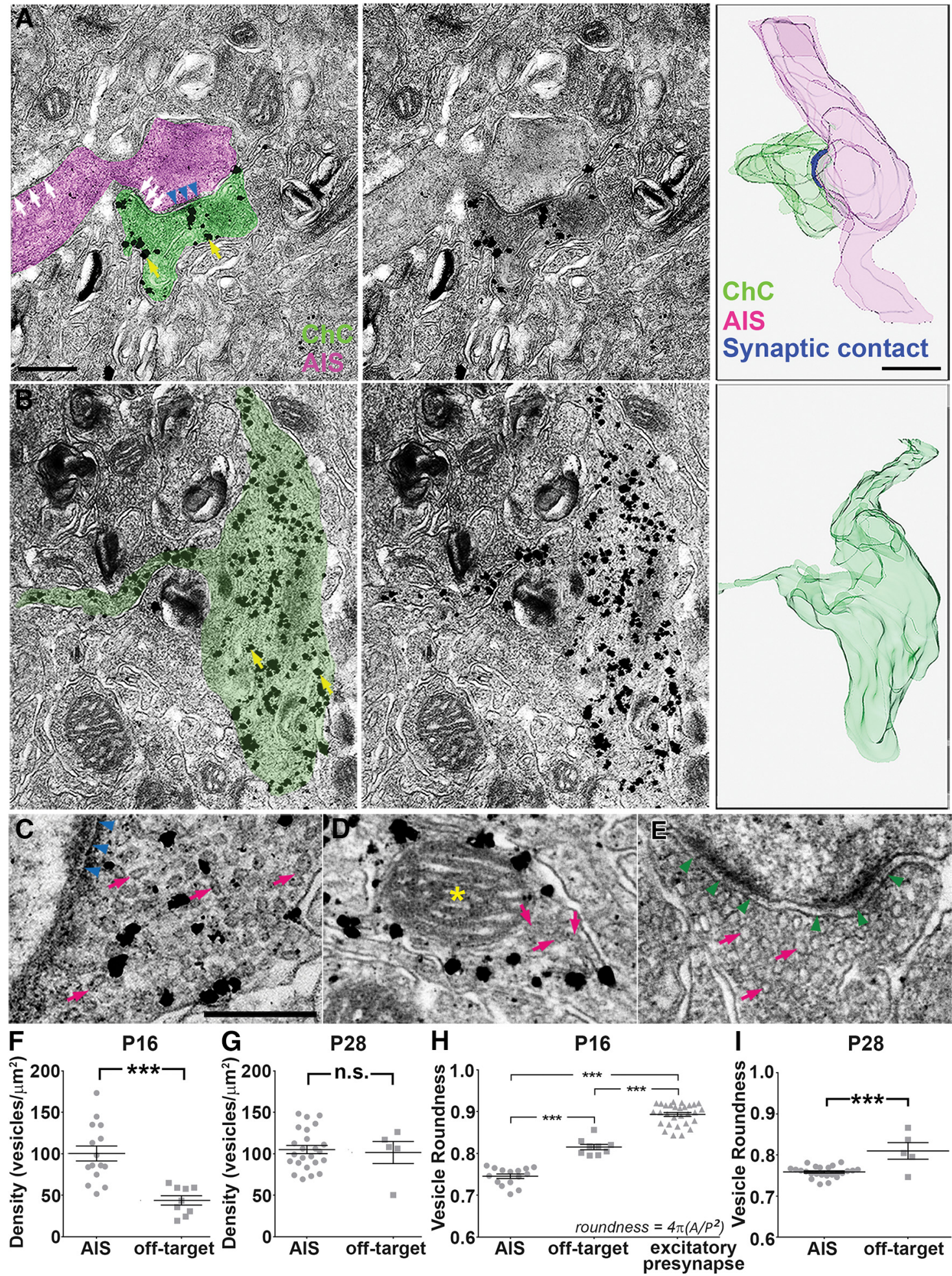

Figure 5. Ultrastructural characterization of AIS and off-target varicosities. $\boldsymbol{A}, \boldsymbol{B}$, Immunoelectron micrographs (left and middle panels) and 3D schematics reconstructed from serial EM sections (right panels) showing an AIS varicosity $(\boldsymbol{A})$ and an off-target varicosity $(\boldsymbol{B})$ in P16 ChCs. ChCs are tagged with tGFP in Nkx2.1-CreER;LSL-tGFP mice. Immunohistochemistry with anti-GFP antibodies and secondary antibodies conjugated with gold particles (yellow arrows) marks ChC axonal terminals. In left panels, varicosities and AISs are overlaid with light green and magenta, respectively. Middle panels show intact images. White arrows denote electron dense axonal membrane profiles, which are typically observed in AISs. Blue arrowheads indicate a symmetric synapse, which represents a GABAergic inhibitory synapse. Scale bar, $500 \mathrm{~nm}$. Note that a clear synaptic profile is visible in an AIS varicosity, whereas there is no sign of a synapse in an off-target varicosity. $\boldsymbol{C}-\boldsymbol{E}$, Electron micrographs showing vesicles (arrows) in an AIS varicosity (C), an off-target varicosity $(\boldsymbol{D})$, and an excitatory presynapse $(\boldsymbol{E})$ at P16. Blue and green arrowheads indicate a symmetric synapse $(\boldsymbol{C})$ and an 


\section{continued}

asymmetric synapse $(\boldsymbol{E})$, respectively. Note distinct vesicle morphology in different types of varicosities (magenta arrows). Mitochondria (yellow asterisk in $\boldsymbol{D}$ ) were frequently found in varicosities. Scale bar, $250 \mathrm{~nm}$. $\boldsymbol{F}$, The average density of vesicles in AIS and off-target varicosities in P16 ChCs. AIS varicosities show a higher density of vesicles than off-target varicosities (AIS, $n=15$ varicosities; off-target, $n=9$ varicosities; 2 ChCs per condition; Student's $t$ test: $* * * p<0.001)^{\mathrm{m}}$. Data are presented as mean \pm SEM. $G$, The average density of vesicles in AIS and off-target varicosities in P28 ChCs. AIS and off-target varicosities show no difference in vesicle density (AIS, $n=24$ varicosities; off-target, $n=5$ varicosities; 2 ChCs per condition; Student's $t$ test: $n . s$. $p=0.78)^{p}$. Data are presented as mean \pm SEM. $\boldsymbol{H}$, The average roundness of vesicles in AIS varicosities, off-target varicosities, and excitatory presynapses at P16. AIS varicosities show the lowest roundness of vesicles, followed by off-target varicosities, and excitatory presynapses (AIS, $n=15$ varicosities; off-target, $n=9$ varicosities; excitatory presynapses, $n=29$ varicosities; 2 ChCs per condition; one-way ANOVA: $* * * p<0.001)^{n}$. Data are presented as mean \pm SEM. $I$, The average roundness of vesicles in AIS and off-target varicosities at P28. AIS varicosities show a lower roundness of vesicles than off-target varicosities (AIS, $n=24$ varicosities; off-target, $n=5$ varicosities; 2 ChCs per condition; Student's $t$ test: $* * * p<0.001)^{q}$. Data are presented as mean \pm SEM.

\section{Subcellular synapse specificity of $\mathrm{ChCs}$ is predetermined}

Previous studies using classical dye-filling and genetic labeling revealed striking subcellular synapse specificity of IN subtypes in mature cortical circuits (Somogyi et al., 1998; Karube et al., 2004; Huang et al., 2007; Jiang et al., 2015). However, it has been an outstanding question how such an elaborate synaptic connectivity emerges during development. Ectopic formation and subsequent elimination of synapses are common strategies for neural circuits to refine connectivity based on the environment and corresponding computational requirements (Katz and Shatz, 1996; Sanes and Lichtman, 1999; Goda and Davis, 2003; Clarke and Barres, 2013; Hashimoto and Kano, 2013). Our finding that ChCs develop an excessive number of offtarget varicosities, which undergo massive pruning, is seemingly consistent with this view because most axonal varicosities have been traditionally considered presynaptic structures (Meyer and Smith, 2006; Ruthazer et al., 2006; Wu et al., 2012). However, our analyses using immunohistochemistry, IEM, and exogenously introduced synaptic markers suggested that although forming varicosities both on and off AISs, ChCs predominantly develop presynapses at AIS varicosities throughout development and maintain this synaptic specificity in young adulthood. We cannot completely exclude the possibility that a small fraction of off-target varicosities form synapses as indeed, $\sim 10 \%$ of off-target varicosities contain presynaptic markers. However, it is hard to imagine that we missed early stage synapses ubiquitously formed at off-target varicosities because similar approaches were used in many other studies to identify nascent synapses (Zito et al., 2009; Wu et al., 2012). Thus, we conclude that subcellular synapse specificity of ChCs is predetermined. It is most likely that molecular cues localized at AISs control target recognition and/or synapse formation by ChCs. In the cerebellum, neurofascin (NF) is expressed in the soma and AIS of Purkinje cells and regulates navigation of basket cell (BC) axons from the soma to the AIS (Ango et al., 2004). Since NF is localized at the AISs of cortical PNs (Hedstrom et al., 2007), it would be of great interest to test whether NF also controls subcellular synapse specificity of ChCs.

\section{Potential roles of off-target varicosities in developing and young adult ChCs}

Our finding of off-target, nonsynaptic varicosities in developing $\mathrm{ChCs}$ raises a question about their role in axonal wiring. Due to the following reasons, we predict that off-target varicosities may serve as initiation sites of filopodia, which are precursors of axonal branches. First, off-target varicosities and branch points concomitantly increase between P12 and P16. Second, axonal varicosities have been shown to serve as hotspots to generate filopodia in different systems including BC axons in the mouse cortex (Wu et al., 2012) and retinal axons in lower vertebrates (Meyer and Smith, 2006; Ruthazer et al., 2006). Third, we found that a significant fraction of offtarget varicosities contain mitochondria, which have been shown to colocalize with branch points and play a role in branching in different types of neurons (Courchet et al., 2013; Spillane et al., 2013). Live imaging of developing ChCs will provide direct evidence for this hypothesis in the future.

Notably, our results showed that young adult ChCs (e.g., P28) retain off-target varicosities even after the pruning phase. Considering the completion of $\mathrm{ChC}$ axonal wiring at P21, we do not expect that these off-target varicosities actively form branches. This is not contradictory to our speculation discussed above if the competence of off-target varicosities to generate filopodia is developmentally downregulated. Recent studies showed that inhibitory INs in adult animals are highly plastic in response to changes in sensory experiences and natural learning and memory paradigms (Keck et al., 2011; van Versendaal et al., 2012; Trouche et al., 2013). Thus, an intriguing possibility is that off-target varicosities of young adult ChCs may serve as cellular devices for the formation of additional branches or synapses when activated by particular stimuli.

\section{ChC axonal arbors are established through remodeling}

Developmental axonal refinement is widely observed in distinct nervous systems, including retinotectal axons, climbing fibers in the cerebellum, and motor axons at neuromuscular junctions (Katz and Shatz, 1996; Sanes and Lichtman, 1999; Goda and Davis, 2003; Clarke and Barres, 2013; Hashimoto and Kano, 2013). Axonal pruning usually occurs in parallel with synaptic pruning. Here we found that $\mathrm{ChCs}$ also undergo striking axonal remodeling to establish highly stereotyped axonal arbor organization with vertically aligned branches. However, interestingly, our data showed that the reduction in the number of branch points starts after ChCs largely complete formation of AIS syn- 
aptic varicosities. Based on this observation, we propose that axonal branches that failed to form synaptic varicosities may be preferentially pruned. Previous results showing that branch retractions halt at synaptic varicosities in developing axonal arbors (Meyer and Smith, 2006; Ruthazer et al., 2006) are consistent with this idea. Long-term live imaging of $\mathrm{ChC}$ axons and synaptic markers in a remodeling phase will provide a definitive answer to this issue.

Previous studies examined developmental processes of axonal arborization in $\mathrm{BCs}$, which innervate perisomatic areas of PNs, and found that there is no obvious axonal overgrowth and pruning: they continuously increased branch numbers until reaching a plateau (Chattopadhyaya et al., 2004). However, because of cellular heterogeneity (Tremblay et al., 2016), substantial branch pruning in a single type of BCs could be hidden in the analysis. Thus, it remains elusive whether other morphologically distinct IN subtypes display developmental axonal remodeling like ChCs. Nevertheless, it would be interesting to speculate a potential reason why $\mathrm{BCs}$ and $\mathrm{ChCs}$ use different developmental processes to organize their axonal arbors. One major difference between BCs and ChCs is in the density of their postsynaptic subcellular targets. As proximal dendrites and cell bodies, which are typical subcellular targets of BCs, are densely intermingled in the cortical neuropil, axonal branches of BCs may easily find synaptic targets and form synaptic varicosities. Indeed, most axonal varicosities of BCs contain presynaptic markers at a light microscopic level (Wu et al., 2012). If synaptic varicosities control branch stability, axonal arbors of BCs would not undergo pruning. In contrast, because AISs are relatively sparsely distributed, a significant fraction of $\mathrm{ChC}$ branches may not be able to form synapses on subcellular targets. These branches free of synaptic varicosities could be retracted.

\section{Conclusion}

In summary, we have provided the first evidence that ChCs establish axonal organization through remodeling but develop subcellular synapse specificity in a predetermined manner. Future studies of the molecular and cellular mechanisms of $\mathrm{ChC}$ wiring will give us important insight into how inhibitory circuits containing diverse IN subtypes are assembled during development. Consistent with their powerful influence on PN spike generation, ChCs have been implicated in the pathology of brain disorders such as schizophrenia (Lewis, 2010) and epilepsy (DeFelipe, 1999). Our results showing the developmental trajectory of $\mathrm{ChC}$ wiring may serve as a reference point to identify pathologic processes in mouse models of these brain diseases.

\section{References}

Angaut P, Sotelo C (1989) Synaptology of the cerebello-olivary pathway. Double labelling with anterograde axonal tracing and GABA immunocytochemistry in the rat. Brain Res 479:361-365. Medline

Ango F, di Cristo G, Higashiyama H, Bennett V, Wu P, Huang ZJ (2004) Ankyrin-based subcellular gradient of neurofascin, an immunoglobulin family protein, directs GABAergic innervation at Purkinje axon initial segment. Cell 119:257-272. CrossRef Medline
Chattopadhyaya B, Di Cristo G, Higashiyama H, Knott GW, Kuhlman SJ, Welker E, Huang ZJ (2004) Experience and activity-dependent maturation of perisomatic GABAergic innervation in primary visual cortex during a postnatal critical period. J Neurosci 24:9598-9611. CrossRef Medline

Chattopadhyaya B, Di Cristo G, Wu CZ, Knott G, Kuhlman S, Fu Y, Palmiter RD, Huang ZJ (2007) GAD67-mediated GABA synthesis and signaling regulate inhibitory synaptic innervation in the visual cortex. Neuron 54:889-903. CrossRef Medline

Clarke LE, Barres BA (2013) Emerging roles of astrocytes in neural circuit development. Nat Rev Neurosci 14:311-321. CrossRef Medline

Courchet J, Lewis TL Jr, Lee S, Courchet V, Liou DY, Aizawa S, Polleux $F$ (2013) Terminal axon branching is regulated by the LKB1-NUAK1 kinase pathway via presynaptic mitochondrial capture. Cell 153:1510-1525. CrossRef Medline

DeFelipe J (1999) Chandelier cells and epilepsy. Brain 122:18071822. CrossRef

DeFelipe J, López-Cruz PL, Benavides-Piccione R, Bielza C, Larrañaga $P$, Anderson $S$, Burkhalter $A$, Cauli B, Fairén A, Feldmeyer D, Fishell G, Fitzpatrick D, Freund TF, González-Burgos G, Hestrin S, Hill S, Hof PR, Huang J, Jones EG, Kawaguchi Y, et al. (2013) New insights into the classification and nomenclature of cortical GABAergic interneurons. Nat Rev Neurosci 14:202-216. CrossRef Medline

De Paola V, Holtmaat A, Knott G, Song S, Wilbrecht L, Caroni P, Svoboda K (2006) Cell type-specific structural plasticity of axonal branches and boutons in the adult neocortex. Neuron 49:861-875. CrossRef Medline

Glickfeld LL, Roberts JD, Somogyi P, Scanziani M (2009) Interneurons hyperpolarize pyramidal cells along their entire somatodendritic axis. Nat Neurosci 12:21-23. CrossRef Medline

Goda Y, Davis GW (2003) Mechanisms of synapse assembly and disassembly. Neuron 40:243-264. Medline

Hashimoto K, Kano M (2013) Synapse elimination in the developing cerebellum. Cell Mol Life Sci 70:4667-4680. CrossRef Medline

Hedstrom KL, Xu X, Ogawa Y, Frischknecht R, Seidenbecher Cl, Shrager P, Rasband MN (2007) Neurofascin assembles a specialized extracellular matrix at the axon initial segment. J Cell Biol 178:875-886. CrossRef Medline

Herman MA, Ackermann F, Trimbuch T, Rosenmund C (2014) Vesicular glutamate transporter expression level affects synaptic vesicle release probability at hippocampal synapses in culture. J Neurosci 34:11781-11791. CrossRef Medline

Howard A, Tamas G, Soltesz I (2005) Lighting the chandelier: new vistas for axo-axonic cells. Trends Neurosci 28:310-316. CrossRef Medline

Huang ZJ, Di Cristo G, Ango F (2007) Development of GABA innervation in the cerebral and cerebellar cortices. Nat Rev Neurosci 8:673-686. CrossRef Medline

Inan M, Blazquez-Llorca L, Merchan-Perez A, Anderson SA, DeFelipe J, Yuste R (2013) Dense and overlapping innervation of pyramidal neurons by chandelier cells. J Neurosci 33:1907-1914. CrossRef

Jenkins SM, Bennett V (2001) Ankyrin-G coordinates assembly of the spectrin-based membrane skeleton, voltage-gated sodium channels, and L1 CAMs at Purkinje neuron initial segments. J Cell Biol 155:739-746. CrossRef Medline

Jiang X, Shen S, Cadwell CR, Berens P, Sinz F, Ecker AS, Patel S, Tolias AS (2015) Principles of connectivity among morphologically defined cell types in adult neocortex. Science 350:aac9462. CrossRef Medline

Jonas P, Bischofberger J, Fricker D, Miles R (2004) Interneuron diversity series: fast in, fast out-temporal and spatial signal processing in hippocampal interneurons. Trends Neurosci 27:30-40. CrossRef

Jones EG (1975) Varieties and distribution of non-pyramidal cells in the somatic sensory cortex of the squirrel monkey. J Comp Neur 160:205-267. CrossRef Medline 
Karube F, Kubota Y, Kawaguchi Y (2004) Axon branching and synaptic bouton phenotypes in GABAergic nonpyramidal cell subtypes. J Neurosci 24:2853-2865. CrossRef Medline

Katz LC, Shatz CJ (1996) Synaptic activity and the construction of cortical circuits. Science 274:1133-1138. Medline

Keck T, Scheuss V, Jacobsen RI, Wierenga CJ, Eysel UT, Bonhoeffer T, Hübener M (2011) Loss of sensory input causes rapid structural changes of inhibitory neurons in adult mouse visual cortex. Neuron 71:869-882. CrossRef Medline

Kepecs A, Fishell G (2014) Interneuron cell types are fit to function. Nature 505:318-326. CrossRef Medline

Klausberger T, Somogyi P (2008) Neuronal diversity and temporal dynamics: the unity of hippocampal circuit operations. Science 321:53-57. CrossRef Medline

Klausberger T, Magill PJ, Marton LF, Roberts JD, Cobden PM, Buzsáki G, Somogyi P (2003) Brain-state- and cell-type-specific firing of hippocampal interneurons in vivo. Nature 421:844-848. CrossRef Medline

Lewis DA (2010) The chandelier neuron in schizophrenia. Dev Neurobiol 71:118-127. CrossRef Medline

Madisen L, Zwingman TA, Sunkin SM, Oh SW, Zariwala HA, Gu H, $\mathrm{Ng}$ LL, Palmiter RD, Hawrylycz MJ, Jones AR, Lein ES, Zeng $\mathrm{H}$ (2010) A robust and high-throughput Cre reporting and characterization system for the whole mouse brain. Nat Neurosci 13:133140. CrossRef Medline

Markram H, Toledo-Rodriguez M, Wang Y, Gupta A, Silberberg G, Wu C (2004) Interneurons of the neocortical inhibitory system. Nat Rev Neurosci 5:793-807. CrossRef Medline

Meyer MP, Smith SJ (2006) Evidence from in vivo imaging that synaptogenesis guides the growth and branching of axonal arbors by two distinct mechanisms. J Neurosci 26:3604-3614. CrossRef Medline

Nishiyama H, Fukaya M, Watanabe M, Linden DJ (2007) Axonal motility and its modulation by activity are branch-type specific in the intact adult cerebellum. Neuron 56:472-487. CrossRef Medline

Palay SL, Sotelo C, Peters A, Orkand PM (1968) The axon hillock and the initial segment. J Cell Biol 38:193-201. Medline

Ruthazer ES, Li J, Cline HT (2006) Stabilization of axon branch dynamics by synaptic maturation. J Neurosci 26:3594-3603. CrossRef Medline

Sanes JR, Lichtman JW (1999) Development of the vertebrate neuromuscular junction. Annu Rev Neurosci 22:389-442. CrossRef Medline
Somogyi P (1977) A specific 'axo-axonal' interneuron in the visual cortex of the rat. Brain Res 136:345-350. Medline

Somogyi P, Tamás G, Lujan R, Buhl EH (1998) Salient features of synaptic organisation in the cerebral cortex. Brain Res Brain Res Rev 26:113-135. Medline

Spillane M, Ketschek A, Merianda TT, Twiss JL, Gallo G (2013) Mitochondria coordinate sites of axon branching through localized intra-axonal protein synthesis. Cell Rep 5:1564-1575. CrossRef Medline

Szabadics J, Varga C, Molnár G, Oláh S, Barzó P, Tamás G (2006) Excitatory effect of GABAergic axo-axonic cells in cortical microcircuits. Science 311:233-235. CrossRef Medline

Szentagothai J (1975) The 'module-concept' in cerebral cortex architecture. Brain Res 95:475-496. CrossRef

Taniguchi H, Lu J, Huang ZJ (2013) The spatial and temporal origin of chandelier cells in mouse neocortex. Science 339:70-74. CrossRef Medline

Taniguchi H, He M, Wu P, Kim S, Paik R, Sugino K, Kvitsiani D, Fu Y, Lu J, Lin Y, Miyoshi G, Shima Y, Fishell G, Nelson SB, Huang ZJ (2011) A resource of Cre driver lines for genetic targeting of GABAergic neurons in cerebral cortex. Neuron 71:995-1013. CrossRef Medline

Tremblay R, Lee S, Rudy B (2016) GABAergic interneurons in the neocortex: from cellular properties to circuits. Neuron 91:260-292. CrossRef Medline

Trouche S, Sasaki JM, Tu T, Reijmers LG (2013) Fear extinction causes target-specific remodeling of perisomatic inhibitory synapses. Neuron 80:1054-1065. CrossRef Medline

van Versendaal D, Rajendran R, Saiepour MH, Klooster J, SmitRigter L, Sommeijer JP, De Zeeuw CI, Hofer SB, Heimel JA, Levelt CN (2012) Elimination of inhibitory synapses is a major component of adult ocular dominance plasticity. Neuron 74:374-383. CrossRef Medline

Woodruff AR, Anderson SA, Yuste R (2010) The enigmatic function of chandelier cells. Front Neurosci 4:201. CrossRef Medline

Wu X, Fu Y, Knott G, Lu J, Di Cristo G, Huang ZJ (2012) GABA signaling promotes synapse elimination and axon pruning in developing cortical inhibitory interneurons. J Neurosci 32:331-343. CrossRef Medline

Zito K, Scheuss V, Knott G, Hill T, Svoboda K (2009) Rapid functional maturation of nascent dendritic spines. Neuron 61:247-258. CrossRef Medline 